\title{
Interaction between Borrelia burgdorferi and Endothelium In Vitro
}

Andrew Szczepanski, Martha B. Furie, Jorge L. Benach, Bernard P. Lane, and Howard B. Fleit
Department of Pathology, State University of New York at Stony Brook, Stony Brook, New York 11794

\begin{abstract}
During the pathogenesis of Lyme disease, Borrelia burgdorferi spreads hematogenously from the site of a tick bite to several tissues throughout the body. The specific mechanism of spirochete emigration is presently unknown. Using cultured human umbilical vein endothelial cells, we found that Borrelia burgdorferi bound to the endothelial cells and to the subendothelial matrix. Low passage isolates adhered 22-30-fold greater than a strain maintained in culture continuously. Spirochete binding to subendothelial matrix was inhibited $48-63 \%$ by pretreatment of the matrix with anti-fibronectin antiserum. Spirochete migration across endothelial monolayers cultured on amniotic membrane was increased when the monolayers were damaged by chemical or physical means. Electron microscopic examination of spirochete-endothelial interactions demonstrated the presence of spirochetes in the intercellular junctions between endothelial cells as well as beneath the monolayers. Scanning electron microscopy identified a mechanism of transendothelial migration whereby spirochetes pass between cells into the amniotic membrane at areas where subendothelium is exposed. (J. Clin. Invest. 1990. 85:1637-1647.) Lyme disease • spirochete $\bullet$ extracellular matrix $\bullet$ fibronectin
\end{abstract}

\section{Introduction}

Lyme disease is a complex multisystemic infectious disorder affecting the skin, heart, nervous system, and joints (1). Presently, this disease is the most prevalent vector-borne infection in the United States (2). The causative agent is a spirochete, Borrelia burgdorferi, which has been isolated from the blood, cerebrospinal fluid, synovial fluid and skin from patients with Lyme disease (3-6). After introduction into the host at the site of a tick bite, the spirochetes presumably spread to secondary sites via the bloodstream. Spirochetes have been demonstrated histologically in sites distant from the initial skin lesion in patients with late manifestations of this disease (7). Moreover, after a brief period of spirochetemia, $B$. burgdorferi has been isolated from several organs in experimentally infected hamsters (8).

To understand better the mechanisms by which spirochetes emigrate from the blood, we have examined interactions between the Lyme disease spirochete and cultured endothelium. Such an in vitro approach has been used by several

Address reprint requests to Dr. Fleit, State University of New York, School of Medicine, Department of Pathology, HSC Tower 9, Room 140, Stony Brook, NY 11794.

Received for publication 28 November 1988 and in revised form 9 October 1989.

J. Clin. Invest.

(c) The American Society for Clinical Investigation, Inc.

$0021-9738 / 90 / 05 / 1637 / 11 \$ 2.00$

Volume 85, May 1990, 1637-1647 other groups studying various microorganisms. Both grampositive and gram-negative bacteria bind to endothelial monolayers $(9,10)$. Candida species bind to endothelial monolayers and to the subendothelial matrices produced by the cells in culture (11-13). Treponema pallidum, the spirochete that causes syphilis, adheres to monolayers of aortic endothelial cells and migrates across the monolayers at the intercellular junctions (14).

The results presented herein demonstrate that Borrelia burgdorferi adhered to cultured human umbilical vein endothelial cells and to the subendothelial matrix. Spirochete binding to subendothelial matrix was significantly reduced by pretreatment of the matrix with antiserum to fibronectin. Spirochete migration across endothelial monolayers was increased after disruption of the monolayers by either chemical or physical means. Transmission electron microscopy demonstrated that the spirochetes penetrated endothelial monolayers at the intercellular spaces.

\section{Methods}

Cultivation of spirochetes. All isolates of Borrelia burgdorferi were subcultured in modified Kelly's medium at $32^{\circ} \mathrm{C}$. Medium, without normal rabbit serum, was supplemented with $0.2 \%$ yeastolate (Difco Laboratories, Detroit, MI) (15). The strains included two low passage human clinical isolates (HSA1, HBD1) cultured from the skin and blood, respectively, of patients with erythema chronicum migrans, a low passage tick isolate (TI1, from Ixodes dammini collected in Montauk, NY) and the continuously passaged strain B31 (1). Borrelia hermsii strain HS1, a gift from Dr. Alan Barbour (University of Texas, San Antonio, TX), was subcultured in BSK II medium at $32^{\circ} \mathrm{C}$.

Radiolabeling of spirochetes. $24-48 \mathrm{~h}$ before use in binding experiments, spirochetes were subcultured in medium containing 10-15 $\left.\mu \mathrm{Ci} / \mathrm{ml} \mathrm{[}{ }^{3} \mathrm{H}\right]$ thymidine $(60-74 \mathrm{Ci} / \mathrm{mmol}$; ICN Radiochemicals, Irvine, CA). Spirochetes were pelleted at $7,000 \mathrm{~g}$ for $15 \mathrm{~min}$ at $20^{\circ} \mathrm{C}$, washed three times in HBSS, and resuspended in RPMI 1640 containing 10 $\mathrm{mg} / \mathrm{ml}$ bovine serum albumin and $10 \mathrm{mM}$ Hepes (Gibco Laboratories, Grand Island, NY) (RBH). ${ }^{1}$ The specific activity of radiolabeled spirochetes was measured for each experiment and expressed as $\mathrm{dpm} / 10^{6}$ organisms.

Preparation of human amniotic membrane. Human amniotic tissue was prepared as previously described (16). In brief, the amnion reflecta was separated from the chorion and fastened to teflon rings (16 $\mathrm{mm}$ i.d., $22 \mathrm{~mm}$ o.d., $9.5 \mathrm{~mm}$ high; providing a $2-\mathrm{cm}^{2}$ area of amnion within each ring) with an O-ring. The teflon rings with attached amnion were removed from the remainder of the placenta and washed extensively with Hepes-buffered saline (HBS) $(137 \mathrm{mM} \mathrm{NaCl}, 4 \mathrm{mM}$ $\mathrm{KCl}, 11 \mathrm{mM}$ glucose, $10 \mathrm{mM}$ Hepes, $\mathrm{pH}$ 7.4) containing penicillin $(500 \mathrm{U} / \mathrm{ml})$ and streptomycin $(200 \mu \mathrm{g} / \mathrm{ml})$. The amnion was then exposed to sterile $0.25 \mathrm{M} \mathrm{NH}_{4} \mathrm{OH}$ for $2 \mathrm{~h}$ at room temperature. The amniotic epithelium was removed by scraping with a rubber policeman. The tissue was washed with HBS to remove cellular debris and the amnion was stored at $4^{\circ} \mathrm{C}$ in $\mathrm{HBS}$ containing penicillin and strep-

1. Abbreviations used in this paper: FBS, fetal bovine serum; HBS, Hepes-buffered saline; HUVEC, human umbilical vein endothelial cells; RBH, RPMI 1640 containing $10 \mathrm{mg} / \mathrm{ml} \mathrm{BSA}$ and $10 \mathrm{mM}$ Hepes. 
tomycin until use. Before addition of endothelial cells, the amnion rings were equilibrated with Medium 199 (M199; Gibco Laboratories) containing 5\% heat-inactivated donor calf serum (Hazelton Research Products, Lenexa, KS), penicillin $(100 \mathrm{U} / \mathrm{ml})$, and streptomycin $(100$ $\mu \mathrm{g} / \mathrm{ml})$.

Endothelial cell culture. Human umbilical vein endothelial cells (HUVEC) were isolated according to the method of Jaffe (17) with the following modifications: the umbilical vein was cannulated with a three-way stopcock containing an O-ring (C. E. Conover, Fairfield, NJ) on its end and fastened in place with $\mathrm{OO}$ silk suture (Ethicon, Somerville, NJ). This procedure was repeated for the opposite end of the vein, and the vessel was washed from each end with $50 \mathrm{ml} \mathrm{HBS}$. Collagenase (CLSII; Worthington, Freehold, NJ) at a final concentration of $0.03 \%$ in HBS was infused into the vein. The cord was then incubated for 12 $\min$ at $37^{\circ} \mathrm{C}$. The collagenase solution was recovered from the vein and the vein was washed once with $25 \mathrm{ml}$ of M199 containing 5\% heat-inactivated donor calf serum. The wash was recovered, added to the collagenase solution, and centrifuged at $800 \mathrm{~g}$. The pellet was resuspended in M199 containing 20\% fetal calf serum (HyClone Laboratories, Logan, UT), penicillin $(100 \mathrm{U} / \mathrm{ml})$, streptomycin $(100 \mu \mathrm{g} / \mathrm{ml})$, and fungizone ( $2 \mu \mathrm{g} / \mathrm{ml}$; Gibco) and plated onto a $60-\mathrm{mm}$ dish precoated with $1.5 \%$ gelatin $(18)$. When the cells reached confluence (within 3-5 d), they were transferred either to gelatin-coated multiwell plates or to amniotic membrane. HUVEC were released from the 60-mm dishes with $0.125 \%$ trypsin and 2 mM EDTA in PBS, and replated onto 24 and 48 well plates at a cell density of $1.35 \times 10^{5} / \mathrm{cm}^{2}$, and onto the amnion at $1.5 \times 10^{5} \mathrm{cells} / \mathrm{cm}^{2}$. Cultures established on amnion were used $7 \mathrm{~d}$ after plating, and the cells plated onto the multiwell plates for adherence assays were used 4-5 d after plating.

Preparation of subendothelial matrix. Subendothelial matrices from HUVEC were prepared as follows. Endothelial cells grown in 24 well plates were washed once with PBS, and then treated with PBS containing $10 \mathrm{mM}$ EDTA for $10 \mathrm{~min}$ at $37^{\circ} \mathrm{C}$. After an additional wash with PBS, the cells were treated with $0.025 \mathrm{~N} \mathrm{NH}_{4} \mathrm{OH}$ for 10 min at $23^{\circ} \mathrm{C}$. Each well was washed three times with $1.0 \mathrm{ml}$ PBS and then once with RBH before the addition of spirochetes. The presence of subendothelial matrix was verified by Coomassie blue staining and direct visualization by bright field microscopy. In some experiments, subendothelial matrices were pretreated with antisera to extracellular matrix proteins. The endothelial cell matrices were incubated with antibodies for $2 \mathrm{~h}$ at $37^{\circ} \mathrm{C}$ and washed twice with $1 \mathrm{ml}$ of $\mathrm{Ca}^{2+}$ - and $\mathrm{Mg}^{2+}$-free PBS before the addition of spirochetes. The following antibodies were tested: rabbit polyclonal anti-human plasma fibronectin antiserum and IgG fraction (Cappel Laboratories, Malvern, PA); rabbit polyclonal anti-Factor VIII related antigen IgG fraction (anti-von Willebrand Factor; Dako Corp., Santa Barbara, CA); goat polyclonal antiserum to human type I, III, or IV collagen (Southern Biotechnology Associates, Birmingham, AL).

Adherence assay. Radiolabeled spirochetes were added to endothelial monolayers or their subendothelial matrices in a total volume of $200 \mu \mathrm{l} /$ well of a $24-$ well plate $(100 \mu \mathrm{l} /$ well for 48 well plates $)$. The plates were incubated for $2 \mathrm{~h}$ at $37^{\circ} \mathrm{C}$ and $5 \% \mathrm{CO}_{2}$. Each well was then washed three times with $0.5 \mathrm{ml} \mathrm{HBSS}(0.25 \mathrm{ml}$ for 48 well plates). The tritium label was solubilized with $0.5 \mathrm{~N} \mathrm{NaOH}$. Each sample was transferred to $5 \mathrm{ml}$ Ecolume (ICN Radiochemicals) and the bound radioactivity was determined in a liquid scintillation counter (LKB Instruments, Inc., Gaithersburg, MD).

Immunoprecipitation of biosynthetically labeled HUVEC monolayers. HUVEC were grown for $4 \mathrm{~d}$ on one gelatin-coated 35-mm dish in RPMI 1640 containing $20 \% \mathrm{FCS}, 10 \mu \mathrm{Ci} / \mathrm{ml}\left[{ }^{3} \mathrm{H}\right.$ ]proline (New England Nuclear, Boston, MA), $25 \mu \mathrm{Ci} / \mathrm{ml}$ Translabel (ICN Radiochemicals, consisting of ${ }^{35} \mathrm{~S}$-labeled cysteine and methionine), 100 $\mathrm{U} / \mathrm{ml}$ penicillin, $100 \mu \mathrm{g} / \mathrm{ml}$ streptomycin, and $2 \mu \mathrm{g} / \mathrm{ml}$ fungizone. Cell supernatants were removed and the cell monolayers and underlying matrix were solubilized in $1 \mathrm{ml}$ of RIPA $(100 \mathrm{mM}$ Tris- $\mathrm{HCl} \mathrm{pH} 7.1$, $1 \%$ sodium deoxycholate, $1 \%$ Triton X-100, $10 \mathrm{mM}$ EGTA, $10 \mathrm{mM}$ EDTA, $0.1 \%$ sodium deoxycholate, $1 \mathrm{mM}$ PMSF) lysis buffer (19). Solubilized cell layers were immunoprecipitated overnight at $4^{\circ} \mathrm{C}$ with either rabbit anti-human plasma fibronectin (Cappel) or normal rabbit serum followed by protein A-Sepharose for $4 \mathrm{~h}$ at $4^{\circ} \mathrm{C}$. Samples were washed and analyzed by SDS-PAGE and visualized by fluorography as previously described (20).

Spirochete transendothelial migration assay. Spirochetes were washed by centrifugation and resuspended in RBH at a concentration of $4 \times 10^{8}$ spirochetes/ml. HUVEC grown on amniotic membrane were either untreated, scraped in the center of the amnion ring with a pipette tip, or treated with $10 \mathrm{mM}$ EDTA for $5 \mathrm{~min}$ at $37^{\circ} \mathrm{C}$. The cultures were then washed once with $\mathrm{RBH}$, and $10^{8}$ spirochetes were added in a total volume of $0.25 \mathrm{ml}$. After a 1 -h incubation at $37^{\circ} \mathrm{C}$, the cultures were washed three times with RBH and fixed for $1 \mathrm{~h}$ at $23^{\circ} \mathrm{C}$ with $10 \%$ buffered formalin. After fixation, the teflon rings were washed overnight in PBS. The rings were then incubated with a saturating amount of $11 \mathrm{GI}$, an IgM monoclonal antibody to the outer surface protein $A$ of the spirochete $(21)$, for $1 \mathrm{~h}$ at $37^{\circ} \mathrm{C}$. The rings were extensively washed in PBS before the addition of a 1:10 dilution of secondary antibody, fluorescein conjugated goat anti-mouse IgM (Cappel Laboratories), for $2 \mathrm{~h}$ at $37^{\circ} \mathrm{C}$. After washing overnight with PBS, the amnion tissue was removed with a cork borer from the teflon rings and mounted on a glass slide with a mounting medium consisting of $90 \%$ glycerol, $10 \%$ PBS and $1 \mathrm{mg} / \mathrm{ml} p$-phenylenediamine (Aldrich Chemical Co., Milwaukee, WI). This latter reagent reduces fluorescent fading (22) and stains the nuclei orange (23). The preparations were observed using an epifluorescent Nikon Labophot microscope at 125 or 500 magnification and photographed with Ektachrome ASA 200 film. For certain experiments, tritium labeled spirochetes were added to HUVEC monolayers or amnion alone. After $60 \mathrm{~min}$ incubation at $37^{\circ} \mathrm{C}$, the samples were washed three times with $\mathrm{RBH}$ and the tissue was removed with a cork borer and placed in $5 \mathrm{ml}$ of Ecolume. The radioactivity associated with each sample was determined by scintillation spectroscopy.

Electron microscopy. For ultrastructural examination of the interaction between the spirochetes and HUVEC monolayers, endothelial cells were grown on $15 \mathrm{~mm}$ diameter round gelatin-coated Thermonox coverslips (Miles Scientific, Naperville, IL) placed in 24-well plates. Spirochetes resuspended in $\mathrm{RBH}\left(10^{8} / 0.5 \mathrm{ml}\right)$ were added to each coverslip, and the 24 well plate was centrifuged at $600 \mathrm{~g}$ for $5 \mathrm{~min}$ at $4^{\circ} \mathrm{C}$. After centrifugation, the plates were incubated at $37^{\circ} \mathrm{C}$ for various time intervals. The coverslips were removed, washed with RPMI 1640 , and fixed in $3 \%$ glutaraldehyde in $0.2 \mathrm{M}$ sodium cacodylate buffer, $\mathrm{pH} 7.4$, at $4^{\circ} \mathrm{C}$. Specimens were further fixed in $1 \% \mathrm{OsO}_{4}$, dehydrated through a graded ethanol series, and embedded in epon. Thin sections were stained with uranyl acetate and lead citrate and observed in a transmission electron microscope (model 10-CA; Carl Zeiss Instruments, Thornwood, NY). Scanning electron microscopy was performed on subendothelial matrix prepared from cells cultured on Thermonox coverslips or on endothelial monolayers cultured on amniotic membrane. Spirochetes $\left(10^{8}\right)$ in $0.25 \mathrm{ml} \mathrm{RBH}$ were added to each teflon ring or coverslip and incubated at $37^{\circ} \mathrm{C}$ for $60 \mathrm{~min}$. After 1 $\mathrm{h}$ the samples were washed with $\mathrm{RBH}$, fixed in $3 \%$ glutaraldehyde in $0.2 \mathrm{M}$ cacodylate buffer, osmicated, dehydrated with ethanol, carried through a graded amyl acetate series and critical point dried in a Polaron critical point drying apparatus using liquid $\mathrm{CO}_{2}$. Specimens were then sputter coated with $20-25 \mathrm{~nm}$ gold palladium and observed in a scanning electron microscope (model 1400; Amray, Bedford, MA).

Statistical analysis. Data were analyzed by Student's $t$ test.

\section{Results}

Adherence of spirochetes to HUVEC. The adherence of several strains of Borrelia burgdorferi to endothelium derived from human umbilical vein was compared (Table I). Two human isolates (HSA 1, HBD1) cultured from the skin and blood, respectively, of patients with erythema chronicum migrans, a low passage tick isolate (TI1), and the continuously passaged 
Table I. Adherence of Borrelia burgdorferi to Endothelial Monolayers

\begin{tabular}{lccr}
\hline \multicolumn{1}{c}{ Borrelia strain } & Spirochetes bound* & Range & $N^{*}$ \\
\hline B. Burgdorferi & & & \\
HBA1 (skin isolate) & 4.92 & $3.30-6.54$ & 2 \\
HBD1 (blood isolate) & $6.60 \pm 1.69^{\S}$ & $4.76-9.38$ & 11 \\
TI1 (tick isolate) & $6.46 \pm 0.07^{\S}$ & $6.38-6.52$ & 3 \\
B31 & $0.22 \pm 0.09$ & $0.16-0.36$ & 4 \\
B. hermsii (HS1) & 0.88 & $0.83-0.92$ & 2
\end{tabular}

Human endothelial cells were isolated from umbilical veins and cultured on gelatin-coated 24-well plates. Tritiated-thymidine labeled $B$. burgdorferi or $B$. hermsii $\left(10^{8} /\right.$ well $)$ were incubated with the endothelial cells for $2 \mathrm{~h}$ at $37^{\circ} \mathrm{C}$ and $5 \% \mathrm{CO}_{2}$. The plates were washed three times with HBSS and bound radioactivity was determined.

* Mean \pm SEM number of spirochetes bound per well $\times 10^{-6}$.

${ }^{\ddagger}$ Number of times strain was tested.

${ }^{8}$ Significantly greater than $\mathrm{B} 31, P<0.001$.

strain B31 were used. After two hours incubation with HUVEC, the low passage spirochetes had adhered to endothelial monolayers at a level of binding that was 22-30-fold greater than B31 $(P<0.001)$. The adherence of Borrelia hermsii strain HS1, which is avirulent in mice, was also examined. HS1 adherence to endothelial cells was significantly lower than the adherence of both HBDI and TI1 $(P<0.001)$. For comparative purposes, only the blood isolate HBD1 and B31 were used for subsequent experiments.

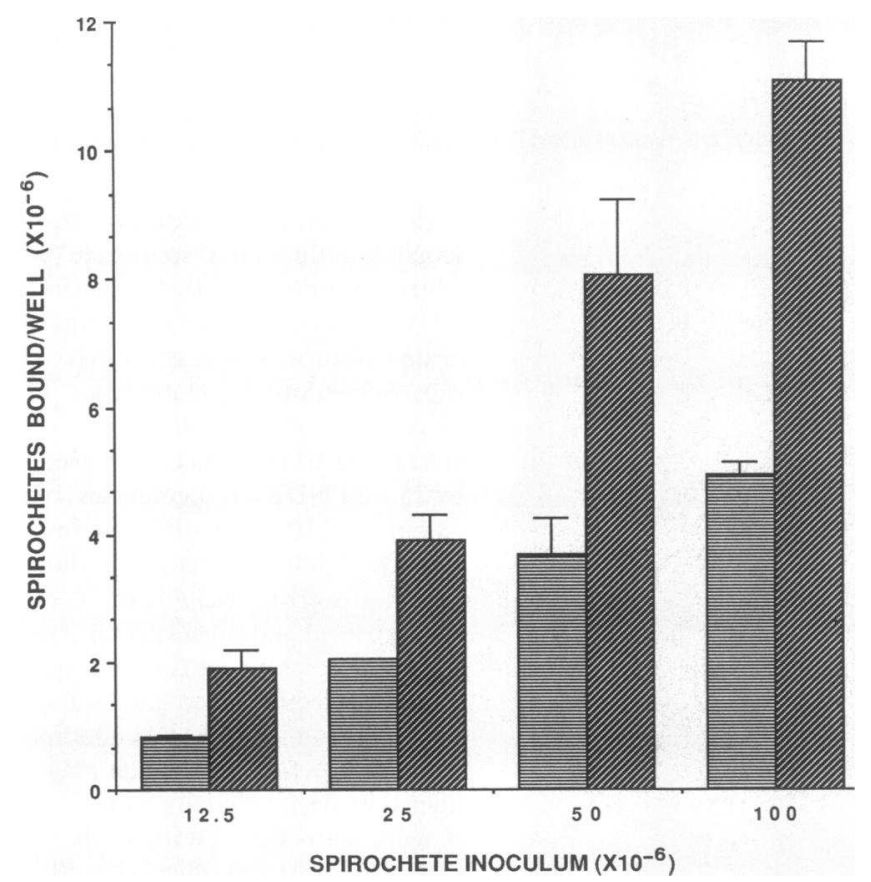

Figure 1. Adherence of Borrelia burgdorferi to human endothelial cells. Endothelial cells isolated from umbilical vein were cultured in gelatin-coated 48-well plates. Tritium labeled spirochetes (strain HBD1) were incubated with the HUVEC monolayers for 2 (⿴囗十) or 4 (घ) at $37^{\circ} \mathrm{C}$. The monolayers were washed and the amount of bound radioactivity was determined. Data points represent the mean $(n$. $=4) \pm \mathrm{SD}$ number of spirochetes bound in a representative experiment repeated three times.
The adherence of $B$. burgdorferi strain HBD1 to endothelial monolayers was both time and inoculum dependent (Fig. 1). Spirochete adherence was examined after 2 and $4 \mathrm{~h}$ incubation with endothelial cells. At both time intervals, the number of adherent spirochetes increased as the inoculum increased from 12.5 to $100 \times 10^{6}$ spirochetes added per well without reaching an apparent saturation. At each inoculum tested from 12.5 to $100 \times 10^{6}$ spirochetes/well, the number of adherent bacteria was greater at the later time interval $(P$ $<0.001$ ).

The specificity of $B$. burgdorferi adherence was examined by incubating radiolabeled spirochetes in the presence of an excess of unlabeled organisms. When $2 \times 10^{7}$ radiolabeled spirochetes (HBD1) were incubated with endothelial monolayers, $1.83 \times 10^{6}(9.12 \%)$ bound to the cells. In the presence of a 50-fold excess of unlabeled HBD1 spirochetes $\left(1 \times 10^{9}\right)$ only $0.57 \times 10^{6}(2.84 \%)$ bound, a reduction of $69 \%(P<0.001)$.

Adherence of $B$. burgdorferi to subendothelial matrix. Cultured umbilical vein endothelial cells produce an extracellular matrix, which resembles the subendothelial basement membrane of these cells in vivo (24). The ability of the spirochetal strains to attach to subendothelial matrix was assessed. Fig. 2 compares the binding of HBD1 and B31 to endothelial monolayers and to the subendothelial matrix remaining after treating the cells with $10 \mathrm{mM}$ EDTA followed by $0.025 \mathrm{~N} \mathrm{NH}_{4} \mathrm{OH}$. As observed for the adherence to endothelial monolayers, the blood isolate bound to the subendothelial matrix to a greater extent than $\mathrm{B} 31,7.0 \pm 1.93 \times 10^{6}$ (nine experiments) vs. $1.47 \pm 0.61 \times 10^{6}$ (three experiments) spirochetes per well, $P$

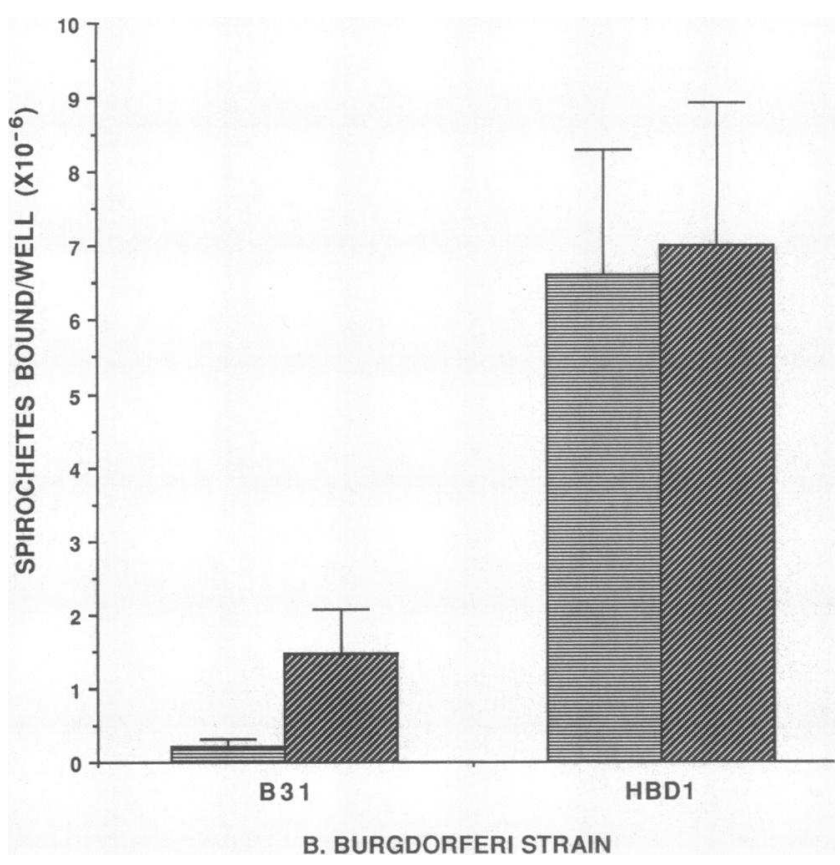

Figure 2. Adherence of Borrelia burgdorferi to endothelial cells (国) and subendothelial matrix (घ). HUVEC were cultured in gelatincoated 24-well plates. Subendothelial matrix was prepared by sequentially treating the cells with $10 \mathrm{mM}$ EDTA and $25 \mathrm{mM}$ $\mathrm{NH}_{4} \mathrm{OH}$. Tritium labeled spirochetes $\left(10^{8} /\right.$ well $)$ were incubated with the cells or matrices for $2 \mathrm{~h}$ at $37^{\circ} \mathrm{C}$. Samples were washed and the bound radioactivity was determined. Data represent the mean \pm SEM of several experiments. 

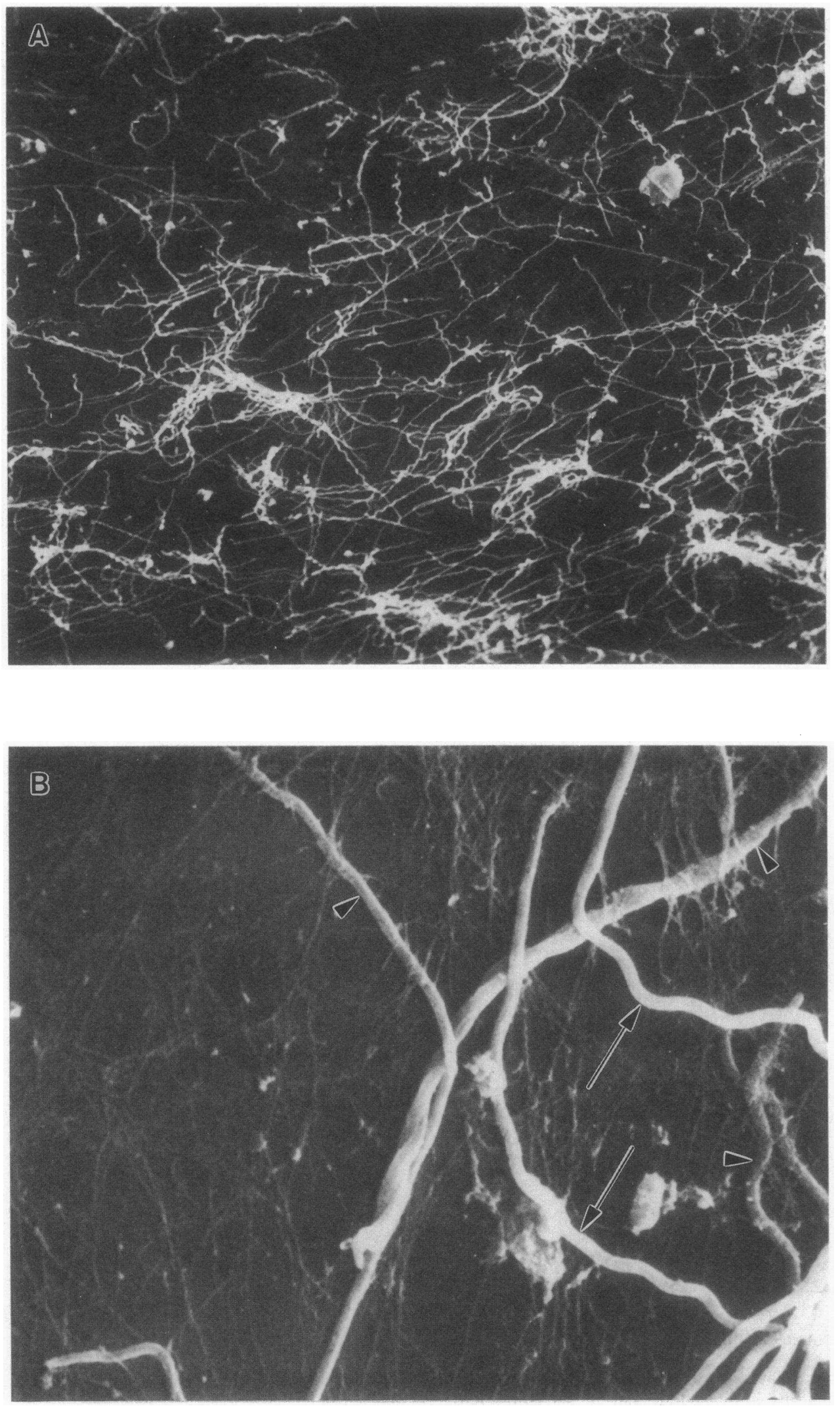

Figure 3. Scanning electron microscopic examination of spirochete adherence to subendothelial matrix. HUVEC were cultured on gelatincoated 15-mm diam plastic coverslips. Subendothelial matrix was prepared by treating cell monolayers with $10 \mathrm{mM}$ EDTA followed by $25 \mathrm{mM} \mathrm{NH}_{4} \mathrm{OH}$. Spirochetes (strain B31, $10^{8} /$ coverslip) were incubated with the matrix preparation for $2 \mathrm{~h}$. Coverslips were then washed, fixed and processed for electron microscopy. $(A)$ Low magnification electron micrograph of spirochetes adherent to subendothelial matrix $(\times 1,340)$. $(B)$ High magnification electron micrograph showing spirochetes on top of the matrix (arrows) and others beneath fibers of the matrix (arrowheads) $(\times 10,700)$.

$<0.001$. While the adherence of HBD1 to cells and subendothelial matrix was comparable, the adherence of B31 to the subendothelial matrix was sevenfold greater than the adherence of this strain to the endothelial cells $(P<0.02)$.
Scanning electron microscopy was performed to analyze the interaction of spirochetes with subendothelial matrix. Spirochetes $\left(10^{8}, \mathrm{~B} 31\right)$ were incubated with matrices for $2 \mathrm{~h}$ at $37^{\circ} \mathrm{C}$. Spirochetes were observed attached to the subendothe- 
lial matrix (Fig. $3 \mathrm{~A}$ ). At higher magnification it was apparent that some spirochetes were lying on top of the matrix (Fig. $3 B$, arrows) while others had migrated into the matrix (arrowheads).

Effect of pretreatment of subendothelium with antibodies to matrix components on spirochete adherence. Subendothelial matrices were pretreated for $2 \mathrm{~h}$ at $37^{\circ} \mathrm{C}$ with antibodies to their components, which had been previously identified using indirect immunofluorescence. Positive staining was observed for fibronectin, von Willebrand factor, and human types I, III, and IV collagen. The matrices did not react with antisera to vitronectin or laminin.

A rabbit polyclonal antiserum against human plasma fibronectin and the IgG fraction of this antiserum significantly reduced the adherence of $B$. burgdorferi to subendothelial matrix. Table II shows the results of a representative experiment comparing the effect of pretreatment of the subendothelial matrix with anti-fibronectin, anti-von Willebrand factor, and anti-collagen antibodies. While anti-collagen types I, III, and IV had no effect on HBD1 adherence, there was a slight reduction with anti-vWF at $1 \mathrm{mg} / \mathrm{ml}$. Anti-fibronectin IgG caused a dramatic reduction in the adherence to matrix with an inhibition of $60 \%(P<0.001)$. Anti-fibronectin IgG at 400 $\mu \mathrm{g} / \mathrm{ml}$ reduced HBD1 adherence $48-63 \%$ in six experiments. Anti-fibronectin also inhibited B31 adherence to subendothelial matrix. Control treated matrices supported the adhesion of $1.87 \pm 0.15 \times 10^{6} \mathrm{~B} 31$, whereas only $0.67 \pm 0.05 \times 10^{6}$ adhered to anti-fibronectin-treated matrices, a $64 \%$ reduction $(P$ $<0.001$ ). Anti-fibronectin IgG inhibited spirochete adherence in a dose-dependent manner. When tested at antibody concentrations of $50,100,200$, and $400 \mu \mathrm{g} / \mathrm{ml}$, spirochete adherence was inhibited $13,30,47$, and $60 \%$, respectively.

To determine the reactivity and specificity of the anti-fibronectin antisera used in these experiments, the rabbit polyclonal anti-fibronectin antiserum was used to immunoprecipi-

Table II. Effect of Matrix Pretreatment on B. burgdorferi Adherence to Subendothelium

\begin{tabular}{lcc}
\hline \multicolumn{1}{c}{ Antibody tested } & Spirochetes bound* & Percent of control \\
\hline $\begin{array}{c}\text { Control NRS IgG } \\
(400 \mu \mathrm{g} / \mathrm{ml})\end{array}$ & $6.20 \pm 0.29$ & 100 \\
$\begin{array}{c}\text { Anti-von Willebrand } \\
\text { factor IgG }(1 \mathrm{mg} / \mathrm{ml})\end{array}$ & $5.37 \pm 0.43$ & 87 \\
$\begin{array}{c}\text { Anti-fibronectin antiserum } \\
(1 \mathrm{mg} / \mathrm{ml})\end{array}$ & $2.76 \pm 0.16$ & $45^{\ddagger}$ \\
$\begin{array}{c}\text { Anti-fibronectin IgG } \\
(400 \mu \mathrm{g} / \mathrm{ml})\end{array}$ & $2.49 \pm 0.16$ & $40^{\ddagger}$ \\
$\begin{array}{c}\text { Anti-collagen type I, III, } \\
\text { and IV }(300 \mu \mathrm{g} / \mathrm{ml})\end{array}$ & $5.99 \pm 0.84$ & 97 \\
\hline
\end{tabular}

Subendothelial matrices were prepared from HUVEC monolayers grown on gelatin coated 24-well plates. Endothelial cells were detached from the matrix by sequential treatment with $10 \mathrm{mM}$ EDTA and $0.025 \mathrm{~N} \mathrm{NH}_{4} \mathrm{OH}$. Matrices were pretreated with antibodies, diluted in RPMI 1640 containing $10 \mathrm{mg} / \mathrm{ml} \mathrm{BSA}$, for $2 \mathrm{~h}$ at $37^{\circ} \mathrm{C}$. Tritium labeled $B$. burgdorferi (strain HBD1, $10^{8} /$ well) were incubated on pretreated matrices for $2 \mathrm{~h}$ at $37^{\circ} \mathrm{C}$. Data represent the mean $(n=4)$ and SE of a representative experiment repeated three times. * Mean \pm SD number of spirochetes bound per well $\times 10^{-6}$.

‡ Significantly lower than control $P<0.001$. tate fibronectin from metabolically labeled HUVEC cultures. The antisera precipitated a single polypeptide, identified by fluorography, which comigrated on SDS-PAGE with plasma fibronectin under nonreducing and reducing conditions.

The effect of soluble fibronectin on spirochete adherence to endothelial monolayers and the subendothelium was assessed by including purified human plasma fibronectin (Cappel) in the adherence assay. Soluble fibronectin was added at a range of concentrations from 0 to $300 \mu \mathrm{g} / \mathrm{ml}$. Soluble fibronectin did not inhibit spirochete adherence to endothelial monolayers or subendothelial matrices at any concentration tested. In addition to fibronectin, several monosaccharides were tested for their effect on spirochete adherence to endothelial cells and subendothelial matrix. L-fucose, $\alpha$-methyl mannoside, galactose, $N$-acetylglucosamine, and $N$-acetylgalactosamine, each at $50 \mathrm{mM}$ failed to inhibit binding to endothelium or subendothelial matrix (data not shown).

The possibility that spirochete adherence to endothelial monolayers was due to fibronectin on the apical surface of the endothelium was examined by preincubating the HUVEC with $400 \mu \mathrm{g} / \mathrm{ml}$ of anti-fibronectin IgG before the addition of radiolabeled spirochetes. This concentration of antibody reduced HBD1 adherence to endothelial monolayers by only $11 \%$ (range 4-11\%), while adherence to the subendothelial matrices produced by endothelium from the same experiment was inhibited $60 \%$ (range 56-63\%).

Visualization of spirochete migration across the endothelium by immunofluorescence. To examine the capacity of the spirochete to migrate through HUVEC monolayers, endothelial cells were grown on amniotic membrane. This in vitro system closely resembles the environment the spirochete encounters when moving out of the bloodstream in vivo. Spirochetes were added to HUVEC monolayers on amnion and incubated for $1 \mathrm{~h}$ at $37^{\circ} \mathrm{C}$. The tissue was washed, fixed, and stained using a mAb to the spirochete surface followed by a fluorescein conjugated secondary antibody. To determine what effect the integrity of the endothelial monolayer had on spirochete migration into the connective tissue of the amnion, some of the HUVEC monolayers were either physically scraped or treated with $10 \mathrm{mM}$ EDTA to expose the connective tissue of the amnion before the addition of spirochetes. Treatment of HUVEC monolayers grown on amnion with 10 mM EDTA reduces the transendothelial electrical resistance by causing retraction of the cells (25). Fig. 4 shows photomicrographs of spirochetes, B31 in $A$ and HBD1 in $B-E$, added to undamaged monolayers $(A-B)$, cells treated with EDTA $(C)$, monolayers that were physically scraped $(D)$, and amnion alone (amnion onto which no cells had been plated, $E$ ). Undisturbed monolayers of HUVEC had few B31 bound to the apical surface (Fig. $4 \mathrm{~A}$ ), with an occasional spirochete migrating through into the connective tissue (not shown). HBD1 bound to untreated monolayers to a greater extent than did B31 (Fig. 4 B). When monolayers were disrupted with EDTA, a much greater spirochete infiltrate was seen at the cellular level (Fig. $4 \mathrm{C}$ ) as well as in the connective tissue below (not shown). Physical scraping, however, led to a more dramatic increase in the number of spirochetes associated with the exposed connective tissue (Fig. $4 \mathrm{D}$ ) when compared to the treatment with EDTA (Fig. $4 C$ ). The binding of spirochetes to the damaged area of the sample was very similar to the binding observed on amnion which contained no endothelium (Fig. $4 E$ ). 

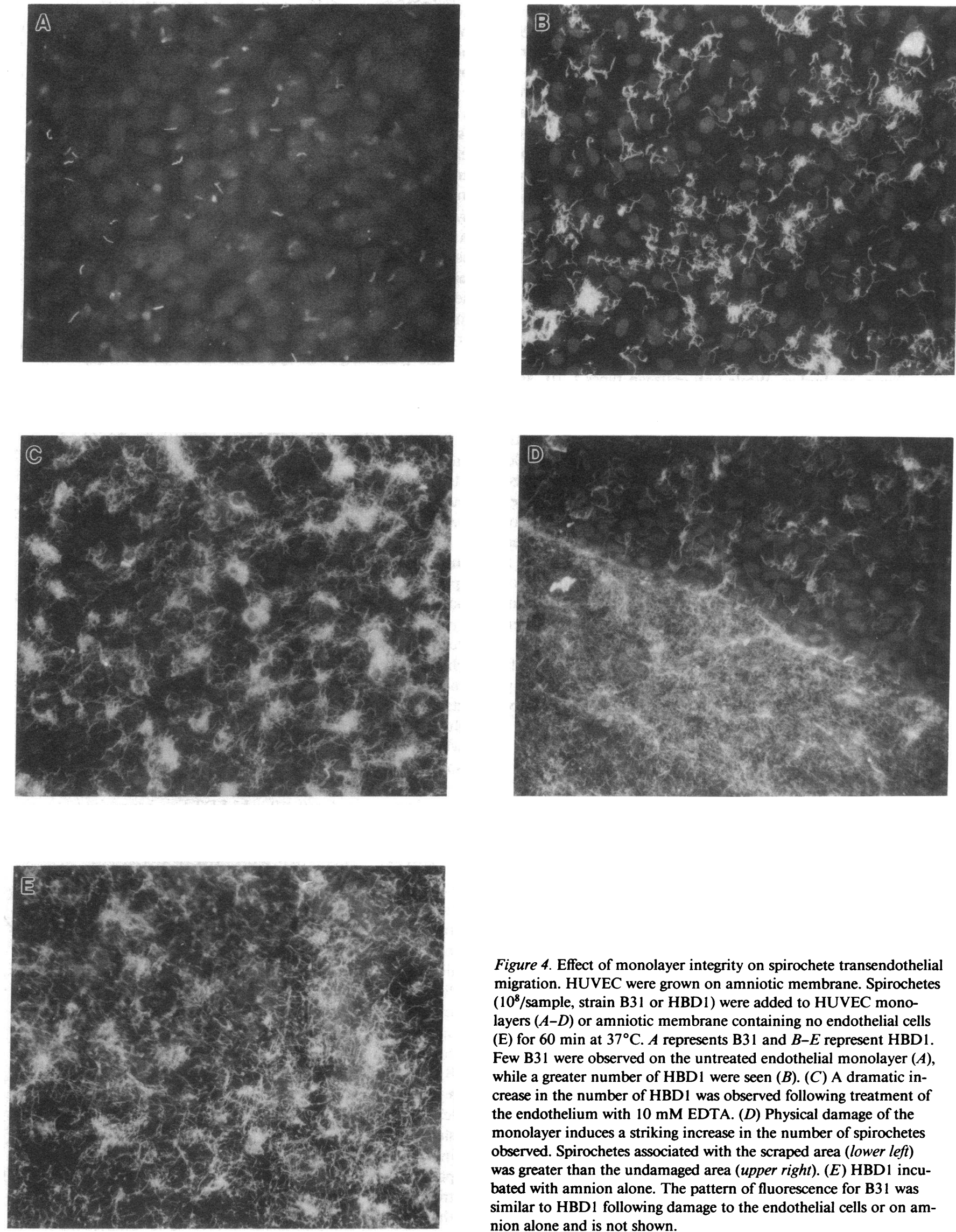

Figure 4. Effect of monolayer integrity on spirochete transendothelial migration. HUVEC were grown on amniotic membrane. Spirochetes $\left(10^{8} /\right.$ sample, strain B31 or HBD1) were added to HUVEC monolayers $(A-D)$ or amniotic membrane containing no endothelial cells (E) for 60 min at $37^{\circ} \mathrm{C}$. $A$ represents $\mathrm{B} 31$ and $B-E$ represent $\mathrm{HBD} 1$. Few B31 were observed on the untreated endothelial monolayer $(A)$, while a greater number of HBD1 were seen $(B) .(C)$ A dramatic increase in the number of HBD1 was observed following treatment of the endothelium with $10 \mathrm{mM}$ EDTA. (D) Physical damage of the monolayer induces a striking increase in the number of spirochetes observed. Spirochetes associated with the scraped area (lower left) was greater than the undamaged area (upper right). (E) HBD1 incubated with amnion alone. The pattern of fluorescence for B31 was similar to HBD1 following damage to the endothelial cells or on amnion alone and is not shown. 
To quantitate the effect of monolayer integrity on spirochete migration into the amnion, radiolabeled spirochetes were added to intact endothelial monolayers, monolayers treated with $10 \mathrm{mM}$ EDTA, or amnion alone. Fig. 5 shows the results of such an experiment comparing the migration of both HBD1 and B31. The migration of HBD1 was greater than B31 in each sample $(P<0.001)$. Also, within each strain the number of migrating spirochetes was greatly increased by disrupting the monolayer or not having one present. These results indicate that the number of spirochetes migrating into the connective tissue as well as the depth of their penetration (not shown) was noticeably reduced in those samples in which the endothelial monolayer was intact.

Ultrastructural examination of spirochete interaction with HUVEC. To examine the mechanism of spirochetal migration across endothelial monolayers by electron microscopy, the cells were cultured on plastic coverslips. Both HBD1 and B31 were used for ultrastructural studies and no differences were observed in their interaction with endothelial monolayers. Spirochetes were centrifuged onto the endothelial cells at $4^{\circ} \mathrm{C}$ and the plates were warmed to $37^{\circ} \mathrm{C}$ for $10-30 \mathrm{~min}$ at which time the coverslips were fixed and processed for transmission electron microscopy. Spirochetes were observed attached to the apical surface of the endothelium (Fig. $6 \mathrm{~A}$ ), including regions of overlap between endothelial cells (Fig. $6 \mathrm{~B}$ ). Spirochetes were also seen in the intercellular spaces between adjacent endothelial cells at varying depths of the monolayer (Fig. $6, \mathrm{C}$ and D). Fig. $6 \mathrm{E}$ represents a spirochete that had com-

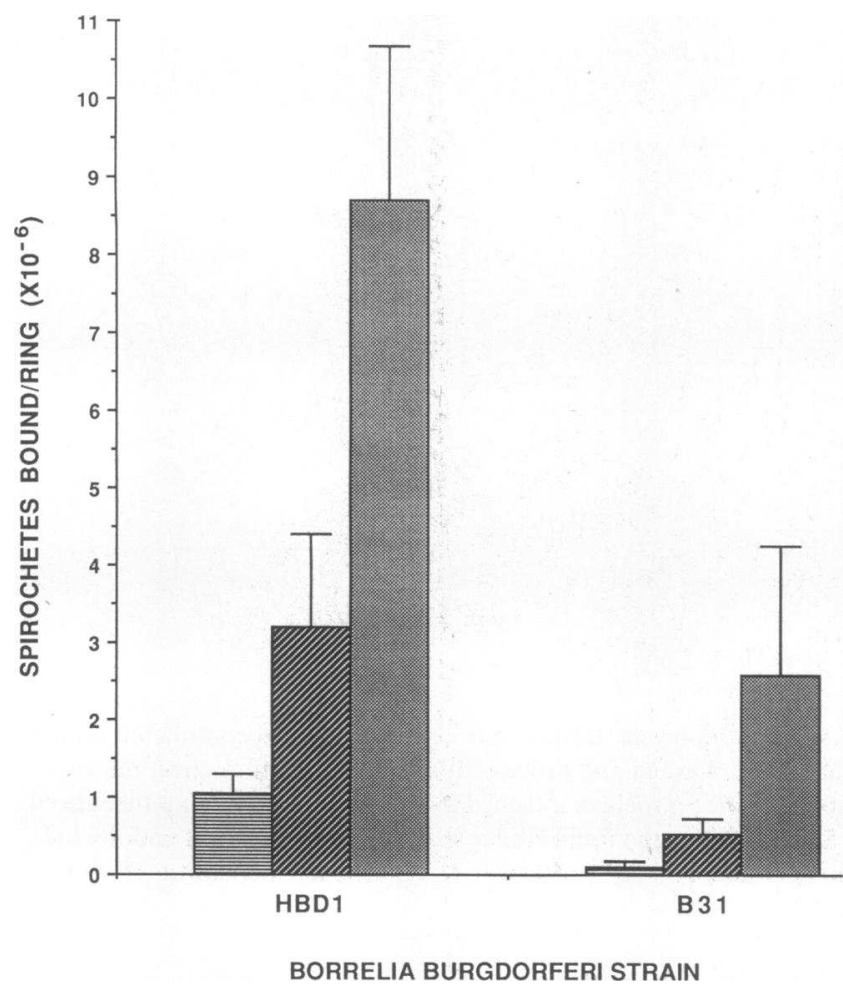

Figure 5. Role of monolayer integrity in spirochete transendothelial migration. HUVEC were cultured on amniotic membrane. Tritiumlabeled B31 or HBD1 $\left(10^{8} /\right.$ sample) were incubated with intact monolayers (国), endothelial cells treated with $10 \mathrm{mM}$ EDTA (国) or amnion alone (ㅁ) for $60 \mathrm{~min}$ at $37^{\circ} \mathrm{C}$. Samples were washed and the associated radioactivity was determined. Data represent the mean ( $n$ $=4) \pm S D$ of a representative experiment repeated twice. pletely penetrated the endothelial monolayer. Fig. $6 F$ depicts a spirochete oriented perpendicular to the monolayer penetrating near a region of intercellular contact between endothelial cells.

Scanning electron microscopy of spirochetes added to HUVEC monolayers grown on amnion and to amnion alone revealed several features of the spirochetal migration process. When spirochetes were incubated with HUVEC monolayers grown on the amnion, the spirochetes were observed penetrating the monolayer at the margins of endothelial cells at sites where subendothelium was exposed (Fig. $7 \mathrm{~A}$ ). Fig. $7 \mathrm{~B}$ shows several portions of spirochetes penetrating from the margin of an endothelial cell. Spirochetes that were incubated on amnion alone were observed penetrating and enclosed within the fibrillar matrix of the connective tissue, demonstrating that the organism did migrate into the dense connective tissue stroma (Fig. 7 C).

\section{Discussion}

During infection with Borrelia burgdorferi, spirochetes spread to secondary sites via the bloodstream. Two important steps during this process are adherence to and penetration across the endothelial surface. In the present study, we demonstrate the adherence of $B$. burgdorferi to human umbilical vein endothelial monolayers and to the subendothelial matrix synthesized by these cells in culture. Spirochete adherence to subendothelial matrix was inhibited by a polyclonal antiserum against human fibronectin. Penetration of endothelial monolayers was dependent on the integrity of the monolayer and was facilitated by damage to the endothelium. Transmission electron microscopy revealed spirochete penetration of endothelium between the cells at the intercellular spaces.

Recent reports have demonstrated the adherence of $B$. burgdorferi to several eukaryotic cell types (26-28). Herein, several strains of $B$. burgdorferi were examined for their capacity to adhere to endothelium in vitro. Three low passage strains, including the human blood isolate HBD1, adhered to endothelial cells in 22-30-fold greater numbers than strain B31, which has been in continuous passage for several years in this laboratory. In addition, the adherence of an avirulent strain of $B$. hermsii was significantly less than adherence of the low passage strains of $B$. burgdorferi. The decreased ability of B31 to adhere to endothelial cells is in agreement with studies that indicate that prolonged in vitro cultivation leads to a reduction in the inability of these spirochetes to infect hamsters experimentally $(8,29)$. The decreased virulence may be due at least in part to a reduction in the ability of the spirochetes to adhere to endothelial cells.

The adherence of $B$. burgdorferi to HUVEC was time and dose dependent. The inability to reach saturation in the adherence assay may be due to the adherence of spirochetes to one another. This tendency to aggregate has been noted in a previous study of $B$. burgdorferi cytadherence (27). Adherence to endothelium was specific since a 50 -fold excess of unlabeled spirochetes significantly reduced the adherence of radiolabeled spirochetes. Although cell surface carbohydrate has been implicated as a receptor for spirochete adherence (26), several monosaccharides including galactose, fucose, $N$-acetylglucosamine, $N$-acetylgalactosamine, and $\alpha$-methylmannoside did not inhibit adherence in our studies.

The adherence of $B$. burgdorferi to subendothelial matrix is an important finding, since spirochetes must penetrate the 

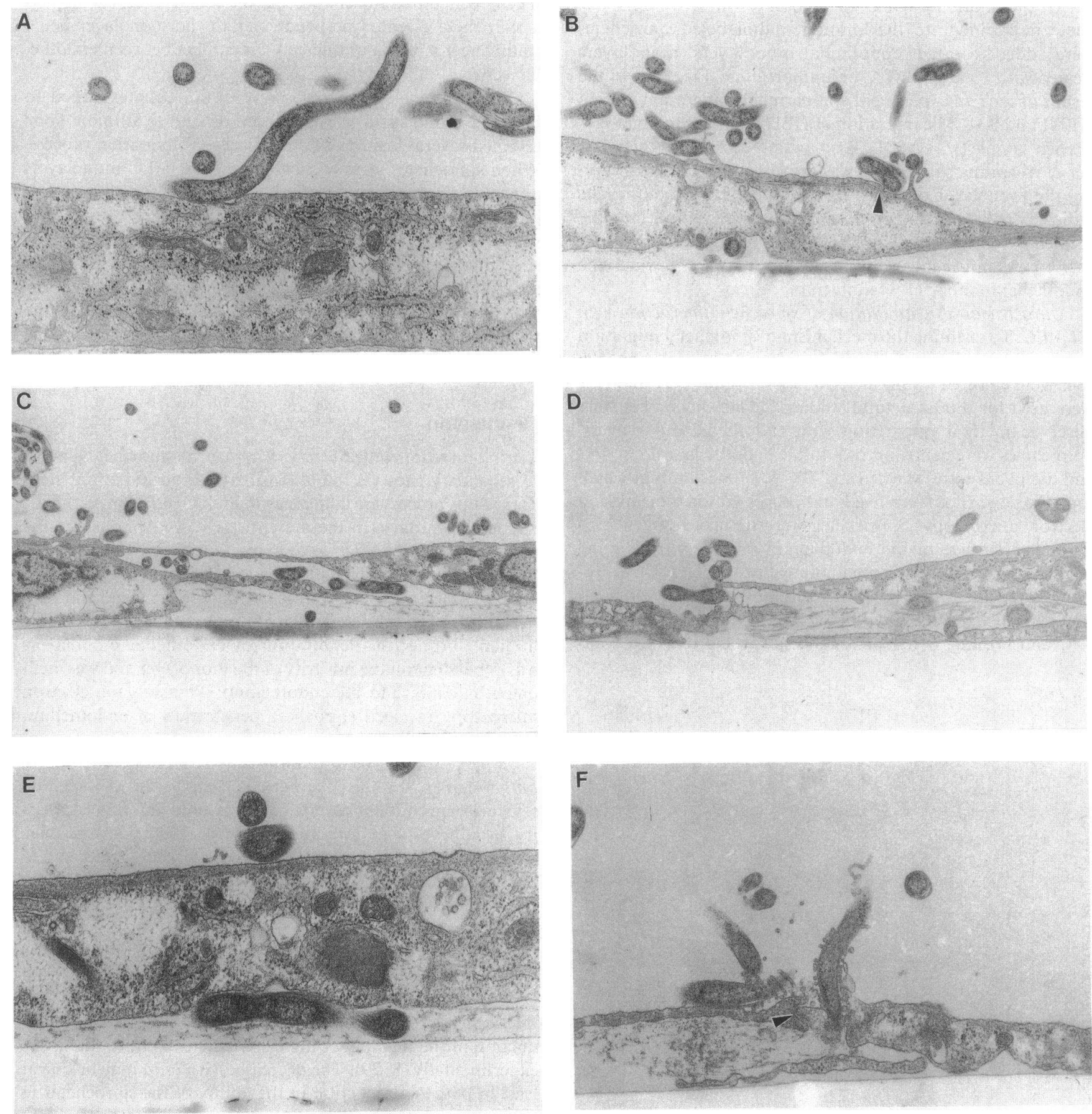

Figure 6. Electron microscopic analysis of spirochete migration across endothelial monolayers. HBD1 were centrifuged onto endothelial monolayers at $600 \mathrm{~g}$ for $5 \mathrm{~min}$ at $4^{\circ} \mathrm{C}$. The samples were then warmed for $10 \mathrm{~min}$ at $37^{\circ} \mathrm{C}$, washed and processed for transmission electron microscopy. $(A)$ Spirochete attached to the apical surface of an endothelial cell $(\times 20,200)$. (B) Spirochete attached to the surface of the endothelial cell above the region of an intercellular junction (arrowhead) $(\times 16,000)$. $(C, D)$ Spirochetes in the intercellular space between adjacent endothelial cells $(\times 10,400[C])(13,100[D])$. $(E)$ Spirochete which has migrated beneath an endothelial cell $(\times 30,400)$. $(E)$ Spirochete penetrating the endothelium at a region near an intercellular junction (arrowhead) $(\times 24,000)$.

subendothelial basement membrane to enter the tissue parenchyma. In the low passage strains, spirochete adherence to the subendothelial matrix was comparable to their adherence to the endothelial monolayer surface and was significantly higher than the adherence of B31 to matrix. Scanning electron microscopy demonstrated that subsequent to attachment spirochetes migrated into the matrix.
Fibronectin is a major component of the matrix produced by cultured endothelial cells $(30,31)$ and is a component of the basement membranes of blood vessels in vivo (32). Analysis of the subendothelial matrix by indirect immunofluorescence indicated that fibronectin was the predominant protein in the matrix. von Willebrand factor and collagens type I, III, and IV were also detected. The inhibition of spirochete adherence to 

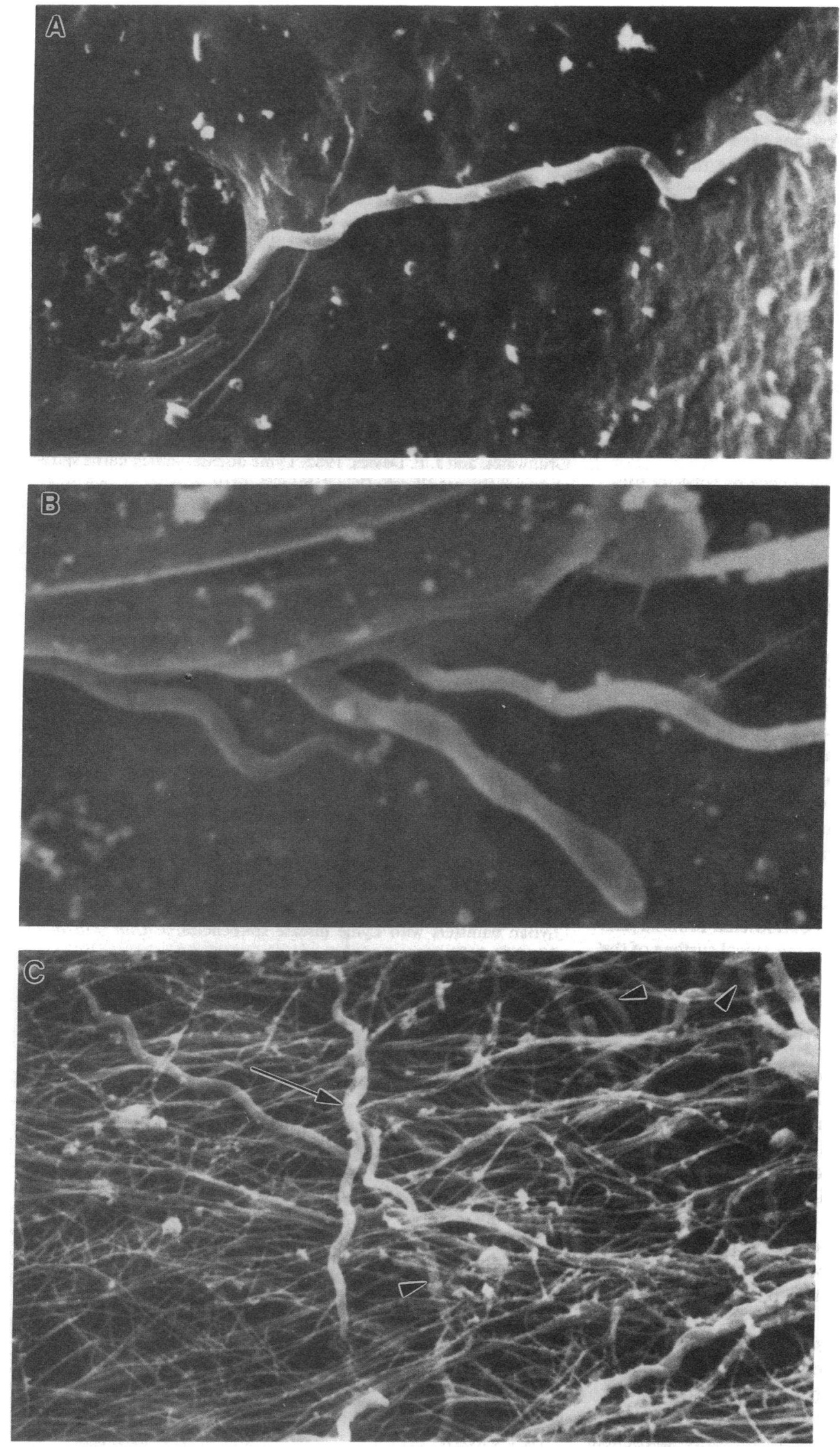

Figure 7. Scanning electron microscopic examination of the interaction between spirochetes and HUVEC or amnion. Spirochetes $\left(10^{8} /\right.$ sample) were incubated with HUVEC cultured on amniotic membrane or amnion alone for 60 $\min$ at $37^{\circ} \mathrm{C}$. $(A)$ A spirochete migrating into the amniotic membrane at the margins between endothelial cells $(\times 10,700)$. $(B)$ Spirochetes migrating beneath the monolayer surface at the periphery of an endothelial cell $(\times 16,500)$. $(C)$ Spirochetes migrating into the fibrous connective tissue of the amniotic membrane. One spirochete is on top of the amnion (arrow) while others have migrated into the connective tissue (arrowheads) $(\times 9,100)$. 
the matrix by anti-fibronectin indicates that the spirochetes recognize the insoluble matrix form of this glycoprotein.

Several bacterial species bind to fibronectin (33-39). Treponema pallidum binds to plasma fibronectin and insoluble fibronectin (33-36). While in the bloodstream, B. burgdorferi would be exposed to high concentrations of soluble plasma fibronectin. However, physiologic concentrations of soluble fibronectin did not inhibit spirochete adherence to subendothelial matrix, indicating that such recognition could occur in the bloodstream. Similar preferential binding of Streptococcus sanguis to insoluble fibronectin has been described previously (39). The molecular basis for such preferential binding is not known. However, it may relate to conformational differences between soluble and insoluble forms of fibronectin. For example, maximal binding of eukaryotic cells to the cell binding fragment of fibronectin requires an alteration of the molecule to an active conformational state (40). Alternatively differences in the primary sequence of the forms of fibronectin may play a role (41).

Spirochete recognition of endothelial cells or subendothelial matrix appears to be mediated by separate mechanisms. Pretreatment of endothelial cells with anti-fibronectin antiserum reduced spirochete adherence to the cells only slightly, while matrix binding was greatly diminished. In addition, little fibronectin is expressed on the surface of endothelial cells both in culture and in vivo $(31,32)$.

The integrity of the endothelial monolayer appears to function as a barrier to spirochete penetration. Spirochete transendothelial migration was facilitated by prior damage of the monolayer by physical or chemical means. Scanning electron microscopy revealed the migration of spirochetes at regions where a small gap in the monolayer exposed the underlying connective tissue. Similar gaps would be expected to exist in vivo, for example in discontinuous sinusoidal endothelium or in areas where endothelial contraction or damage has occurred.

Transmission electron microscopy revealed the mechanism of $B$. burgdorferi penetration of endothelial monolayers. Spirochetes were observed attached to the apical surface of the cells, in the intercellular spaces between cells and also beneath the endothelial monolayers. Spirochete migration occurred via an intercellular route and not by a transcytotic process. This sequence of events was recently described for the transendothelial migration of Treponema pallidum (14). The treponemes migrated across aortic endothelial cells at the intercellular junctions. The presence of intracellular $B$. burgdorferi during migration across endothelial monolayers has been described (42). However, the enclosure of spirochetes within endothelial vesicles was not observed in the present study. However, in rare instances, it appeared that spirochetes might be penetrating directly through endothelial cells in areas of attenuated cytoplasm, located near the periphery. Confirmation of such a transcytotic mechanism will require careful examination of serial sections.

The ability of Borrelia burgdorferi to penetrate the endothelium is a part of the development of disseminated Lyme disease. The observations reported here utilize an in vitro model to identify a mechanism by which Borrelia burgdorferi migrate across endothelium as a system to study spirochete dissemination. The results indicate that spirochetes attach to the endothelial surface or to exposed subendothelial basement membrane and migrate between endothelial cells either at their junctions or at an area that has exposed subendothelial structures.

\section{Acknowledgments}

These studies were supported by an award from the Sinsheimer Foundation to Dr. Fleit, a-grant-in-aid from the American Heart Association and fellowship from the Aaron Diamond Foundation to Dr. Furie, and an award from the G. Harold and Leila Y. Mathers Foundation and National Institutes of Health grant 27044 to Dr. Benach. We thank Gail S. Habicht and James P. Quigley for critical review of the manuscript and Ed Drummond and Barry Burbach for their technical assistance with the electron microscopy. We also thank the Labor and Delivery departments of Brookhaven Memorial Hospital, Patchogue, NY, and St. Charles Hospital, Port Jefferson, NY, for providing human umbilical cords.

\section{References}

1. Burgdorfer, W., A. G. Barbour, S. F. Hayes, J. L. Benach, E. Grunwaldt, and J. P. Davies. 1982. Lyme disease-a tick borne spirochetosis? Science (Wash. DC.) 216:1317-1319.

2. Steere, A. C. 1989. Lyme disease. N. Engl. J. Med. 321:586-596.

3. Benach, J. L., E. M. Bosler, J. P. Hanrahan, J. L. Coleman, G. S. Habicht, T. F. Bast, D. J. Cameron, J. L. Ziegler, A. G. Barbour, W. Burgdorfer, R. Edelman, and R. A. Kaslow. 1983. Spirochetes isolated from the blood of two patients with Lyme disease. N. Engl. J. Med. 308:740-742.

4. Steere, A. C., R. L. Grodzicki, A. N. Kornblatt, J. E. Craft, A. G. Barbour, W. Burgdorfer, G. P. Schmid, E. Johnson, and S. E. Malawista. 1983. The spirochetal etiology of Lyme disease. N. Engl. J. Med. 308:733-740.

5. Schmidli, J., T. Hunziker, P. Moesli, and U. B. Schaad. 1988. Cultivation of Borrelia burgdorferi from joint fluid three months after treatment of facial palsy due to Lyme borreliosis. J. Infect. Dis. 158:905-906.

6. Berger, B. W., O. J. Clemmensen, and A. B. Ackerman. 1983. Lyme disease is a spirochetosis. Am. J. Dermatopathol. 5:111-124.

7. Duray, P. H., and A. C. Steere. 1988. Clinical pathologic correlations of Lyme disease by stage. Ann. NY Acad. Sci. 539:65-79.

8. Johnson, R. C., N. Marek, and C. Kodner. 1984. Infection of Syrian hamsters with Lyme disease spirochetes. J. Clin. Microbiol. 20:1099-1101.

9. Vercelloti, G. M., D. Lussenhop, P. K. Peterson, L. T. Furcht, J. B. McCarthy, H. S. Jacob, and C. F. Moldow. 1984. Bacterial adherence to fibronectin and endothelial cells: a possible mechanism for bacterial tissue tropism. J. Lab. Clin. Med. 103:34-43.

10. Ogawa, S. K., E. R. Yurberg, V. B. Hatcher, M. A. Levitt, and F. D. Lowy. 1985. Bacterial adherence to human endothelial cells in vitro. Infect. Immun. 50:218-224.

11. Rotrosen, D., J. E. Edwards, T. R. Gibson, J. C. Moore, A. H. Cohen, and I. Green. 1985. Adherence of Candida to cultured vascular endothelial cells: mechanisms of attachment and endothelial penetration. J. Infect. Dis. 152:1264-1274.

12. Klotz, S. A. 1987. The adherence of Candida yeasts to human and bovine vascular endothelium and subendothelial extracellular matrix. FEMS (Fed. Eur. Microbiol. Soc.) Microbiol. Lett. 48:201205.

13. Klotz, S. A., and R. D. Maca. 1988. Endothelial cell contraction increases Candida adherence to exposed extracellular matrix. Infect. Immun. 56:2495-2498.

14. Thomas, D. D., M. Navab, D. A. Haake, A. M. Fogelman, J. N. Miller, and M. A. Lovett. 1988. Treponema pallidum invades intercellular junctions of endothelial cell monolayers. Proc. Natl. Acad. Sci. USA. 85:3608-3612.

15. Benach, J. L., H. B. Fleit, G. S. Habicht, J. L. Coleman, E. M. Bosler, and B. P. Lane. 1984. Interactions of phagocytes with the Lyme disease spirochete: role of the Fc receptor. J. Infect. Dis. 150:497-507. 
16. Furie, M. B., E. B. Cramer, B. L. Naprstek, and S. C. Silverstein. 1984. Cultured endothelial monolayers that restrict the transendothelial passage of macromolecules and electrical current. J. Cell Biol. 98:1033-1041.

17. Jaffe, E. A., R. L. Nachman, C. G. Becker, and C. R. Minick. 1973. Culture of human endothelial cells from umbilical vein. J. Clin. Invest. 52:2745-2756.

18. Folkman, J., C. C. Haudenschild, and B. R. Zetter. 1979. Long term culture of capillary endothelial cells. Proc. Natl. Acad. Sci. USA. 76:5217-5221.

19. Cheresh, D. A., and R. C. Spiro. 1987. Biosynthetic and functional properties of an arg-gly-asp-directed receptor involved in human melanoma cell attachment to vitronectin, fibrinogen and von Willebrand Factor. J. Biol. Chem. 262:17703-17711.

20. Fleit, H. B., and M. Kuhnle. 1988. Biochemical characterization of an Fc-receptor purified from human neutrophils. J. Immunol. 140:3120-3125.

21. Benach, J. L., J. L. Coleman, and M. G. Golightly. 1988. A murine monoclonal antibody binds to an antigenic determinant in outer surface protein A, an immunodominant basic protein of the Lyme disease spirochete. J. Immunol. 140:265-272.

22. Johnson, G. D., and G. M. de C. Noguiera Araujo. 1981. A simple method of reducing the fading of immunofluorescence during microscopy. J. Immunol. Methods. 43:349-350.

23. Fleit, H. B., S. D. Wright, C. J. Durie, J. E. Valinsky, and J. C. Unkeless. 1984. Ontogeny of FC receptors and complement receptor (CR3) during human myeloid differentiation. J. Clin. Invest. 73:516525.

24. Levene, C. I., C. P. Bartlet, and G. Heale. 1988. Identification of the connective tissue synthesized by the venous and arterial endothelia of the human umbilical cord: a comparative study. Br. J. Exp. Pathol. 69:177-188.

25. Huang, A. J., M. B. Furie, S. C. Nicholson, J. Fischbarg, L. S. Leibovitch, and S. C. Silverstein. 1988. Effects of human neutrophil chemotaxis across human endothelial monolayers on the permeability of these monolayers to ions and macromolecules. J. Cell. Physiol. 135:355-366.

26. Benach, J. L., J. L. Coleman, J. C. Garcia-Monco, and P. C. Deponte. 1988. Biological activity of Borrelia burgdorferi antigens. Ann. NY Acad. Sci. 539:115-125.

27. Garcia-Monco, J. C., B. Fernandez-Villar, and J. L. Benach. 1989. Adherence of the Lyme disease spirochete to glial cells and cells of glial origin. J. Infect. Dis. 160:497-506.
28. Thomas, D. D., and L. E. Comstock. 1989. Interaction of Lyme disease spirochetes with cultured eucaryotic cells. Infect. Immun. 57:1324-1326.

29. Schwan, T. G., W. Burgdorfer, and C. F. Garon. 1988. Change in infectivity and plasmid profile of the Lyme disease spirochete, Borrelia burgdorferi, as a result of in vitro cultivation. Infect. Immun. 56:1831-1836.

30. Jaffe, E. A., and D. F. Mosher. 1978. Synthesis of fibronectin by cultured human endothelial cells. J. Exp. Med. 147:1779-1791.

31. Birdwell, C. R., D. Gospodorowicz, and G. L. Nicholson. 1978. Identification, localization and role of fibronectin in cultured endothelial cells. Proc. Natl. Acad. Sci. USA. 75:3273-3277.

32. Stenman, S., and A. Vaheri. 1978. Distribution of a major connective tissue protein, fibronectin in normal human tissues. J. Exp. Med. 147:1054-1064.

33. Peterson, K. M., J. B. Baseman, and J. F. Alderete. 1983. Treponema pallidum receptor binding proteins interact with fibronectin. J. Exp. Med. 157:1958-1970.

34. Steiner, B. M., and S. Sell. 1985. Characterization of the interaction between fibronectin and Treponema pallidum. Curr. Microbiol. 12:157-162.

35. Thomas, D. D., J. B. Baseman, and J. F. Alderete. 1985. Fibronectin mediates Treponema pallidum cytadherence through recognition of fibronectin cell-binding domain. J. Exp. Med. 161:514-525.

36. Thomas, D. D., J. B. Baseman, and J. F. Alderete. 1986. Enhanced levels of attachment of fibronectin-primed Treponema pallidum to extracellular matrix. Infect. Immun. 52:736-741.

37. Mosher, D. F., and R. A. Proctor. 1980. Binding and factor $\mathrm{XIII}_{\mathrm{a}}$-mediated cross-linking of a 27 -kilodalton fragment of fibronectin to Staphylococcus aureus. Science (Wash. DC.) 209:927-929.

38. Courtney, H. S., I. Ofek, W. A. Simpson, D. L. Hasty, and E. H. Beachey. 1986. Binding of Streptococcus pyogenes to soluble and insoluble fibronectin. Infect. Immun. 53:454-459.

39. Lowrance, J. H., D. L. Hasty, and W. A. Simpson. 1988. Adherence of Streptococcus sanguis to conformationally specific determinants of fibronectin. Infect. Immun. 56:2279-2285.

40. Schwarz, M. A., and R. L. Juliano. 1984. Surface activation of the cell adhesion fragment of fibronectin. Exp. Cell Res. 153:550-555.

41. Hynes, R. O., and K. M. Yamada. 1982. Fibronectins: Multifunctional modular glycoproteins. J. Cell Biol. 95:369-377.

42. Comstock, L. E., and D. D. Thomas. 1989. Penetration of endothelial cell monolayers by Borrelia burgdorferi. Infect. Immun. 57:1626-1628. 